\title{
Strategic of Applying Free Chemical Usage In Purified Water System For Pharmaceutical Industry Toward CPOB (Cara Pembuatan Obat yang Baik) Indonesia To Reducing Environmental Pollution
}

\author{
R. Kartono ${ }^{1}$, Y. T. Basuki ${ }^{2}$ \\ ${ }^{1}$ Bina Nusantara University, Doctorate Research Management Program, Jakarta, Indonesia \\ ${ }^{2}$ Bina Nusantara University, Doctorate Research Management Program, Jakarta, Indonesia
}

\begin{abstract}
The purpose of this paper is to examine the sets of model and literature review to prove that strategy of applying free chemical usage in purified water system for pharmaceutical industry would be help the existing and new pharmaceutical companies to comply with part of Natioanal Agency of Drug and Food Control / Badan Pengawas Obat dan Makanan (NADFC/BPOM) regulation in order to achieve "Cara Pembuatan Obat yang Baik" (CPOB) of Indonesia pharmaceutical industry. One of the main reasons is when we figured out the number of Indonesian pharmaceutical industries in 2012 are kept reducing compare to the increasing numbers of Indonesian population growth. This strategy concept also might help the industries to reducing environmental pollution, and operational cost in pharmaceutical industries, by reducing of the chemical usage for water treatment process in floculation and cougulation and chlorination for sterillization. This new model is free usage of chemicals for purified water generation system process and sterilization. The concept offering of using membrane technologyReverse Osmosis (RO) membrane base treatment to replace traditional chemical base treatment, following enhance Electrodeionization (EDI) as final polisher for controlling conductivity, and finally Ultra Violet (UV) disinfectant technology as final guard for bacteria controls instead of chemical base system in purified water generation system.
\end{abstract}

Key words - Purified water system, pharmaceutical industry, free chemical, membrane base treatment and enviromental pollution.

\section{Introduction}

As the world fourth largest population country, the numbers of population in Indonesia is estimated around 220 millions, with an annual growth rate of $1.5 \%$ per annum (International Trade Centre, 2005). While, based on Gabungan Perusahaan Farmasi (Indonesian Association of Pharmaceutical Companies), the numbers of pharmaceutical company keep decreasing from year to year. In the earlier 2005, there are around 250 manufacturers of pharmaceutical company and today there are only 199 manufacturers of pharmaceutical company spread around major city in Indonesia in the year 2012. Supposedly, there should be huge potential market for pharmaceutical industry to growth in Indonesia when we compare the numbers of population and the numbers of pharmaceutical company but the fact is the other way round.

Based on the Business Monitor International (2010) report, the main regulatory in Indonesia pharmaceutical industry is the government-controlled National Agency of Drug and Food Control / Badan Pengawas Obat dan Makanan (NADFC/BPOM). The agency was created in 2001 as a part of a major restructuring of the regulatory system. It has broader authority than its predecessor, and reports directly to the president. Its main objectives are to protect the population from unsafe therapeutic products and traditional medicines. BPOM claims to prioritize accelerating the drug approval process and improving transparency.

Since 2001, there are lots of regulations controlled by NADFC/BPO for pharmaceutical industry; therefore there were also lots of pharmaceutical company closed down or bankrupt because of this regulation. And what we try to discussed in this paper is the regulation of pharmaceutical water as one of the strictly regulation that controlled by NADFC/BPOM was concerning of application guidelines for making a good medicine / Cara Pembuatan Obat yang Baik (CPOB) stated in NADFC/BPOM's regulation No. HK. 03.1.33.12.12 year 
2012 was regarding how to process, produce, maintain and sanitation of the purified water system (generation and looping) for pharmaceutical industry in Indonesia.

In recent globalization and the development superhighway have brought countries of the world closer, from a business perspective, the world in one market place, therefore the Indonesian pharmaceutical industry need to learned from the world leader pharmaceutical industry (such as US, Japanese and European Pharmaceutical Industry) in the purified water system for pharmaceutical industry [4].

The pharmaceutical water systems are critical in parental aseptic manufacturing processes because of their influence on final product quality [11]. Water of pharmaceutical quality is mainly used as part of the product in formulation processes and as a cleaning agent for vessels and accessories in direct contact with the product, so it must strictly fulfil chemical and microbiological specifications established in internationally recognized monographes such as United Stated Pharmacopeia (USP) and the European Pharmacopeia (EP). While in Indonesia, CPOB will be recognized by the pharmaceutical companies as a guideline to produce purified water systems.

The standard purified water (PW) system in the pharmaceutical industry as USP guidlines require a conductivity limit of $0.6-4.7 \mu \mathrm{S} / \mathrm{cm}$, a total organic carbon or total oxidizable carbon (TOC) limit of $500 \mathrm{ppb}$, and a bacteria count limit of $100 \mathrm{cfu} / \mathrm{mL}$, the conductivity limit is determined by of three stage processes that accounts for the temperature and $\mathrm{pH}$ of water. While sterile water for injection, irrigation and for inhalation products reffered to water for injection (WFI), with some standard of PW, with endotoxin limet of 0.25 endotoxin units $/ \mathrm{mL}$, and more stricly micro bacteria count limit of $10 \mathrm{cfu} / \mathrm{mL}$.

Most pharmaceutical industries in Indonesia currently use the conventionally purified water treatment processes, with chemical process for purified, and use cation or anion exchange process for conductivity control, and chlorination process for the bacteria control, as we known those proceses are highly chemical usage process, with impacting the high of the environmental pollution and high cost of operational.

In this paper we offering the comprehenship strategic solution to adress of those issues, with free chemical usage system, by using of membrane technology for water purified system, electrodeionization (EDI) for conductivity control and ultra violet (UV) irradiation system for bacteria control.

\section{Literature Review}

The pharmaceutical manufactures are awash in information of data [5]. Laboratory and manufacturing information, non-conformance data and corrective and preventive action (CAPA) plans, clinical trial reports, supplier audits and correspondence with regulatory agencies, customers and other stake holders, including the Goverment policies, all flow into the ever increasing information. When data and information meets the CPOB administration's definition, the company will be record to be readily retrievable and available for review in the next future to maintaining the business sustainability.

In the pharmaceutical industry, customer integration and technology integration are crucial capacity for the new product development strategy [6]. Technology integration is the capacity to link the evolving base of technical knowledge to the existing base of capability within the organization. And also new competences cannot simply be acquired by reactively scanning the existing pool of available technical information.

The role of the global (Information Technology) organization in a pharmaceutical company today is to enhance the company's ability to innovate and enable ever-higher levels of pharmaceutical innovation [13].

Water is one of the major commodities used by the pharmaceutical industry. It may be presented as an excipient, or used for reconstitution of products, during synthesis, during production of finished product or as a cleaning agent for rinsing vessels, equipment, and primary packing materials [7].

Furthermore, purified water is also commonly used in various preparations for pharmaceutical solutions and other applications such as cleaning of semi-critical devices, cleaning facilities and equipment [7]. It is commonly used as the main component in peritoneal dialysis solutions in hospitals, in nutrient solutions (including baby formula) and liquid nutrient solutions prepared in the hospital nursery, for administration to children and debilitated patients.

As a business, the main objectives is an improving the profitability and survival from the environmental pressure [9]. The tension between maximizing of their profit and compliance of the Goverment regulation especially in environmental policy often lead the organization to meet but not necessarily exceed.[10]

In other way the organization have to mandatory meet the environmental requirements. Complying the environmental pressure mostly impacting to the inclining the operational cost.

\section{Discussions}

\subsection{Methodology Approach}

Based on the literature review offering the basic model of technology in purified water system for pharmaceutical industry as per Fig.1 [7].

Every pharmaceutical, chemical and bio technological plant related to health products must rely on appropriate water purification system, permitting it to meet its particular requirements, especially as to the problems related to storage and internal distribution. This procedure must guarantee supply according to the volume required and pursuant to the demanded quality consumption points [7].

The system has pretreatment, particel filter, and the main water treatment is a Reverse Osmosis (RO), with the conductivity control after Rom and sterilized by UltraViolet ( UV). 

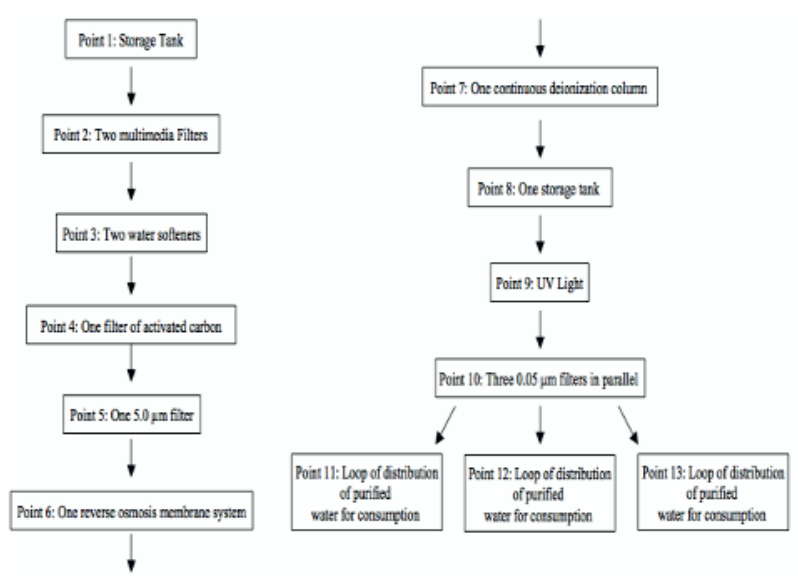

Figure 1. Model of purified water system in pharmaceutical industry. (Mazzola, P.G., et al., 2006)

This sysem is comply with CPOB (Cara Pembuatan Obat yang Baik) in Indonesia, we will be further elaborate this system become an complete integrated system for a new model to applying in purified water system for pharmaceutical industry. The systematically approach will see in the Fig.2.

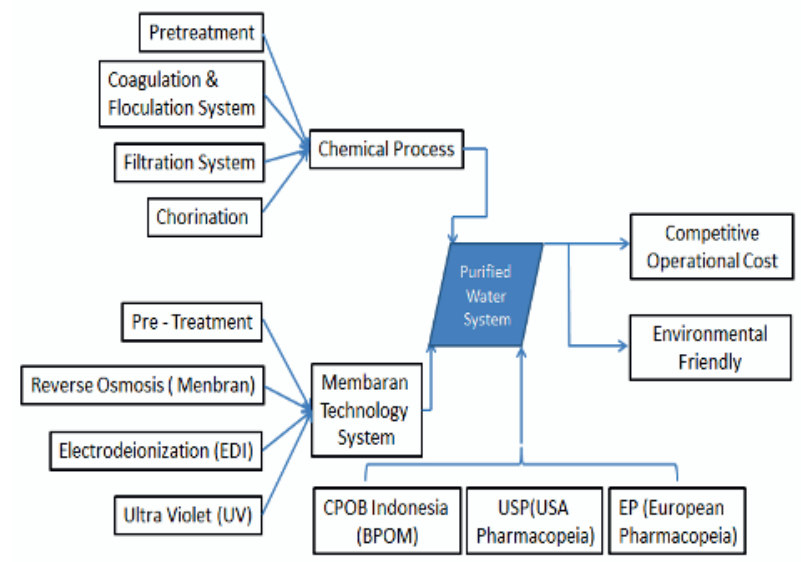

Figure 2. Systematically Approach for Comparation of Chemical and Membrane Technology

There are lots of informations needed in order to produce and manufacture purified water system in the pharmaceutical industry. First of all we need to have a proper documentation and information of user requirement specification (URS), compliance of the Goverment regulation, basic seminar information and standars, and rely with the GP Farmasi Indonesia (Indonesian Association of Pharmaceutical Companies) as the basic foundation information to tell the customer requires, what specification that needs to be adhered to, how much water is needed, what the water system is to do, and what quality specification should comply, etc.

For this reason, every pharmaceutical, chemical and bio technological plant related to health products must rely on appropriate water purification system, permitting it to meet its particular requirements, especially as to the problems related to storage and internal distribution. This procedure must guarantee supply according to the volume required and pursuant to the demanded quality consumption points [7].
Technological process of purified water based on the Velio Pharmaceutical Pure Water Guide, Purify water system use in the pharmaceutical industry, usually requires a series of purification stages. The overall objective is to remove the impurities in the feed water while minimizing additional contamination from the components of the purification system and from bacterial growth.

The selections of the initial stages of a purification system will depend on the characteristics of the feed water quality. The primary purpose of the pre-treatment stages is to reduce damage to subsequent components, to ensure reliable operation of the water purification system, and to decrease the cost of operation by preventing excessively frequent replacement of more expensive components.

The pre-treatment process oftenly uses of technologies such as multimedia filter is a method to prevent the suspended solids from passing through, hold the particles as loosely as possible in order to provide easy back wash and accordingly the performance of multimedia filter could remove $95 \%$ of particles and remove $60 \%$ plus of organic matter, see the pretreatment process in Fig.3.

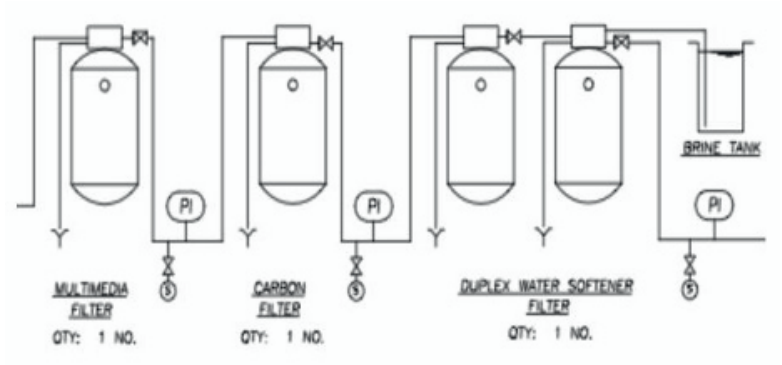

Figure 3. Systematically Approach for pre-treatement process

Following by the activated carbon filter as a method of filtering that uses of a piece of activated carbon to remove the contaminants and impurities, and utilizing chemical adsorption. Carbon filters are most effective technology at removing chlorine, color, sediment and volatile organic compounds (VOCs) from raw water.

Alternatively the softener filter was also involved as the proven technology and technique of ion exchange for producing treated water with low residual hardness and adsorption to prepare the water for purification state and to prevent damage to the membrane technologies used.

\subsection{Chemical Treatment Process of Purified Water}

The process usually use the chemical reaction with directly processes through coagulation and floculation together. The coagulation process involves adding chemical, usually use iron salt or aluminum salts or iron, such as aluminum sulphate, ferric sulphate, ferric chloride, polymers, or polyaluminium chloride (PAC) to the water. These chemicals are called coagulants, and have a positive charge. The positive charge of the coagulant neutralizes the negative charge of dissolved and suspended particles in the water. When this reaction 
occurs, the particles bind together, this process is also called flocculation. The larger particles, or floc, are heavy and quickly settle to the bottom of the water supply. This settling process is called sedimentation.

In a water treatment facility, the coagulant is added to the water and it is rapidly mixed, so that the coagulant is circulated throughout the water. The coagulated water can either be filtered directly through a medium filter (such as sand and gravel), a microfiltration or ultrafiltration membrane, or it can be moved to a settling tank. In a settling tank, or clarifier, the heavy particles settle to the bottom and are removed, and the water moves on to the filtration step of the treatment process.

The time of sedimentation settling, really depend of the particel content in the raw water, will see in Fig. 4 in below:

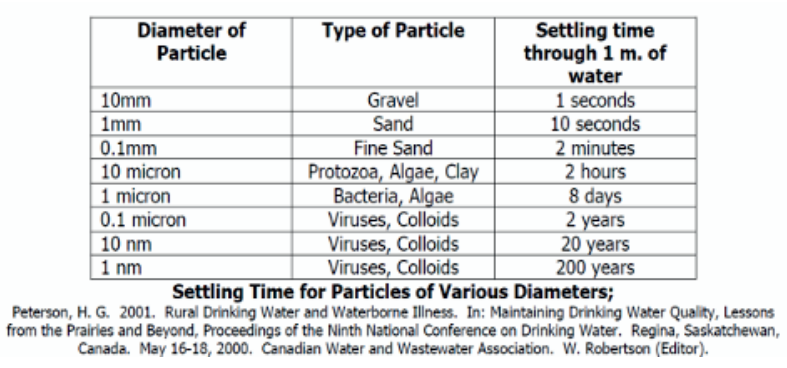

Figure 4. Settling Time for Partical of Raw Water.

To find the dosis of chemical what we have to add in the water in the coagulation and floculation process, generally use the test in labolatory, the process is called a jar test.

With accurate dosages and proper application, the residuals of the added chemicals generally do not pose a problem. Residuals are the by-products that remain in the water after substances are added and reactions occur within the water. The particular residuals depend on the coagulant that is used. If ferric sulphate is used, iron and sulphate are added to the water. If ferric chloride is used, iron and chloride are added. And if aluminum sulphate is used, aluminum and sulphate are added. The majority of municipal water treatment plants use aluminum sulphate as the coagulation chemical.

The next step in a conventional water treatment system is filtration, the objective of this porcess is removes particulate matter from water by forcing the water to pass through porous media. The filtration system consists of filters with varying sizes of pores, and is often made up of sand, gravel and charcoal. The diameter of a grain of fine sand is approximately 0.1 millimetre, so only particles with diameters less than 0.1 millimetre would pass through the fine sand layer. This filter would not be able to produce safe drinking water, because many contaminants are much smaller than 0.1 millimetre (such as viruses, which diameter can be as small as 0.000001 millimetre ) still pass to the after process water treatment.

The sterilization of water, use desinfection process, with objective to kill micro organisme and bacteria in the water. The process commonly use chorine liquid or gas.

Base on the research the cost of this process are in between IDR 3,960 up to IDR 10,040 per M3 of water, depend of the quality of raw water as a main water source. The high contaminant will impacted to the high of the cost of treated the water.

\subsection{Membrane Technology Process of Purified Water}

According to the Velio Pharmaceutical Pure Water Guide' Reverse Osmosis (RO) membranes are used to remove contaminants that are less than $1 \mathrm{~nm}$ nominal diameter.

Reverse osmosis typically removes $90 \%$ to $99 \%$ of ionic contamination, most organic contamination, and nearly all-particulate contamination from raw water. Reverse osmosis is the separation of one component of a solution from another component by means of pressure exerted on a semi permeable membrane. Feed water is high pressure separated with cross flow membrane process into two streams: permeable (product water) and concentrate (rejected salt). Permeate/product water contains less concentration of ionic, organic and suspended/dissolved impurities, while the concentrat contains high concentration of impurities.

Furthermore, RO water treatment has become the standard at many pharmaceutical water treatment plants [8]. RO technology can be a cost effective replacement for dual cation and anion. Please see the membrane system of water purification in Fig. 5 .

The research of the industries, the average cost of the treatment are in U\$ 0,4 up to 0,75 per M3 of water output.

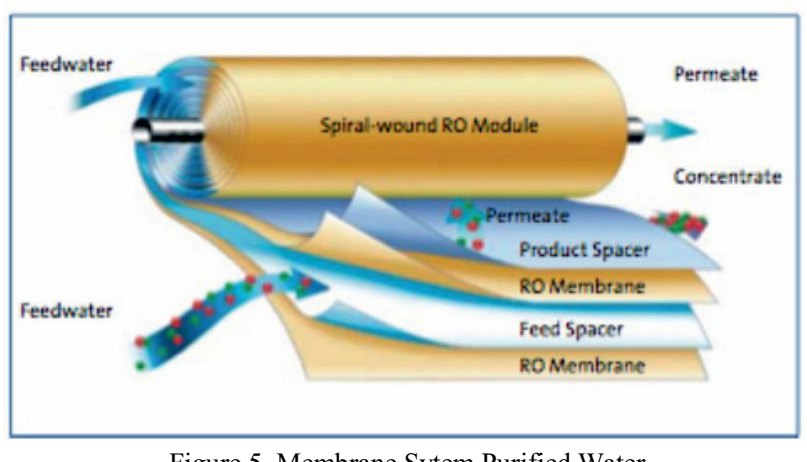

Figure 5. Membrane Sytem Purified Water

\subsection{Electrodeionization Technology (EDI)}

According to the Velio Pharmaceutical Pure Water Guide, Continuous electrodeionisation is a technology combining ion exchange resins and ion-selective membranes with direct current to remove ionised species from water. It was developed to overcome the limitations of ion exchange resin beds, notably the release of ions as the beds exhaust and the associated need to change or regenerate the resins.

The Electro-deionization (EDI) is a technology that uses ion-exchange resin sheets and beads as well as electrical potential to remove undesirable contaminants from pretreated feed water [8]. A significant advantage to using this technology is place of conventional mixed-bed 
technology is the elimination of the need for on-site regeneration chemicals.

Furthermore, EDI is preferred for many purified water generation applications in pharmaceutical industry, because of its "clean" non- chemical nature and constant high quality water produced. Fig. 6 is a deionization process.

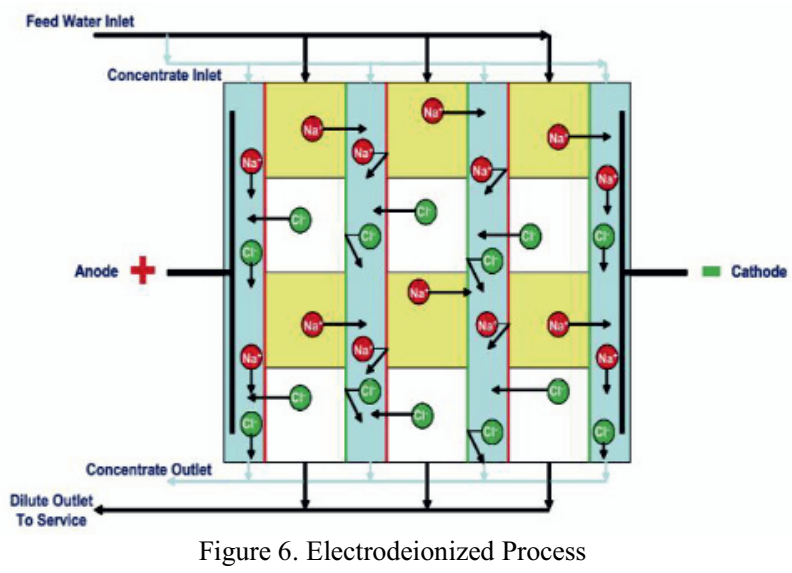

\subsection{Complying The CPOB Indonesia (Cara Pembuatan Obat yang Baik)}

Refer to Velio Pharmaceutical Pure Water Guide stated that Purified water is used in most ppharmaceutical manufacturing processes all around the world. Therefore, international and Indonesia national authorities have established water quality standards for purified and other "regulated" grades of water. The key authorities include:

a. The United States Pharmacopoeia (USP)

b. The European Pharmacopoeia (EP)

c. The Japanese Pharmacopoeia (JP)

The American pharmaceutical industry has played a pioneering role in the development of the drug industry through in-depth, timely and useful research and bulk manufacturing of drug products [4]. Although US pharmaceutical industry in enjoying the leadership position, it can no longer be content to focus only on the USP (United States Pharmacopeia), it also must considered EP (European Pharmacopeia) and JP (Japanese Pharmacopeia).

In Fig. 7 explaining the detail requirements of the pharmacopoeia requrements base on USP and EP :

\begin{tabular}{|c|c|c|}
\hline \multicolumn{3}{|c|}{ Pharmacopoeia requirements for 'purified water' } \\
\hline Properties & Ph Eur & USP \\
\hline Conductivity & $\left\langle 4.3 \mu \mathrm{s} / \mathrm{cm}\right.$ at $20^{\circ} \mathrm{C}$ & $\left\langle 1.3 \mu \mathrm{S} / \mathrm{cm}\right.$ at $25^{\circ} \mathrm{C}^{\circ}$ \\
\hline TOC & $<500 \mu g / l C^{* *}$ & $<500 \mathrm{ppb}$ \\
\hline Bacteria (guideline) & $\angle 100 \mathrm{CFU} / \mathrm{ml}$ & <100 CFU/ml \\
\hline Nitrates & $<0.2 \mathrm{ppm}$ & - \\
\hline Heavy metals & $<0.1 \mathrm{ppm}$ & - \\
\hline
\end{tabular}

Figure 7. Standar Quality of Pharmaceutical Purified Water

Unfortunately, until today there was no any official statement from our Indonesia National Agency of Drug and Food Control/Badan Pengawas Obat dan Makanan
(NADFC/BPOM), regarding which regulation should our $\mathrm{CPOB}$ to be authorized. Therefore, the standard will follow to combine USP (United States Pharmacopeia) and EP (European Pharmacopeia) to meet and comply the regulations and standards of purified water for CPOB in Indonesia pharmaceutical industry.

The standard of Indonesia Pharmacopoeia will use pricesely parameters in the conductivity comparing to the EP Standard. The paramaters standard will see in the Fig. 8 below.

\begin{tabular}{|llll|}
\hline Properties & LSP & Ph Eur & CPOB Indonesin \\
\hline Conductivity & $<1.3 \mu \mathrm{S} / \mathrm{cm}$ & $<4.3 \mu \mathrm{S} / \mathrm{cm}$ & $<1.3 \mu \mathrm{S} / \mathrm{cm}$ \\
& & & \\
\hline TOC & $<500 \mathrm{ppb}$ & $<500 \mu \mathrm{g} / 1$ & $<500 \mathrm{ppb}$ \\
& & & \\
\hline Microbiological & $<100 \mathrm{CFU} / \mathrm{ml}$ & $<100 \mathrm{CFU} / \mathrm{ml}$ & $<100 \mathrm{CFU} / \mathrm{ml}$ \\
& & & \\
\hline
\end{tabular}

Figure 8. Standar Quality of Indonesia Pharmacopoeia

Different grades of water quality are required depending on pharmaceutical uses. Control of the quality of water, in particular, the microbiological quality, is a major concern and the pharmaceutical industry devotes considerable resource to the development and maintenance of water purification systems [7]. For this purpose, the UV irradiation may be implemented to the bacterial control of purified water effluents [8].

\subsection{Environmental Issues}

Conventional water treatment system, moslly use coagulation process. The coagulation process involves adding iron or aluminum salts, such as aluminum sulphate, ferric sulphate, ferric chloride or polymers, to the water. These chemicals are called coagulants, and have a positive charge. The positive charge of the coagulant neutralizes the negative charge of dissolved and suspended particles in the water. When this reaction occurs, the particles bind together, or coagulate (this process is sometimes also called flocculation). The larger particles, or floc, are heavy and quickly settle to the bottom of the water supply. This settling process is called sedimentation.

Coagulation can successfully remove a large amount of organic compounds, including some dissolved organic material, which is referred to as Natural Organic Matter (NOM) or Dissolved Organic Carbon (DOC). Coagulation can also remove suspended particles, including inorganic precipitates, such as iron. A large amount of DOC can give water an unpleasant taste and odour, as well as a brown discolouration. In generally, water treatment facilities have the coagulation process set up so that the coagulant chemicals are removed with the floc. However, it is widely accepted that treatment facilities that use aluminum based coagulants often have higher levels of aluminum in their treated water, but not by much. In Canada, Health Canada has different guideline parameters for treatment facilities that do not use aluminum based coagulants (i.e., $0.1 \mathrm{mg} / \mathrm{L}$ ) and those that do (i.e., $0.2 \mathrm{mg} / \mathrm{L})^{3}$. 
In the process of the sterilitation, the conventional coagulation and sedimentation can only remove between 27 and 84 percent of viruses and between 32 and 87 percent of bacteria $^{3}$. Usually, the pathogens that are removed from the water are removed because they are attached to the dissolved substances that are removed by coagulation. As coagulation does not remove all of the viruses and bacteria in the water, it cannot produce safe drinking water. It is, however, an important primary step in the water treatment process, because coagulation removes many of the particles, such as dissolved organic carbon, that make water difficult to disinfect. Because coagulation removes some of the dissolved substances, less chlorine must be added to disinfect the water. Beside the coagulant, in the conventional water treatment have to add chlorine for bacteri control.

\subsection{Indonesia water pollution}

In 2012, Indonesia has 199 pharmaceutical companies, and in 2012 the growth of this industries reached until $14 \%$, so the water usage for pharmaceutical also increase, and the waste aslo increase inline with the water usage in this sector.

Indonesia river environmental polution condition in 2012 represent in Fig 9. If compare to the Indonesia regulation PP No.82, Tahun 2001, the maximum of COD is in $25 \mathrm{mg} / \mathrm{L}$, refer to figure 6 , all Provinces in the left top quadrant are already polluted.[12]

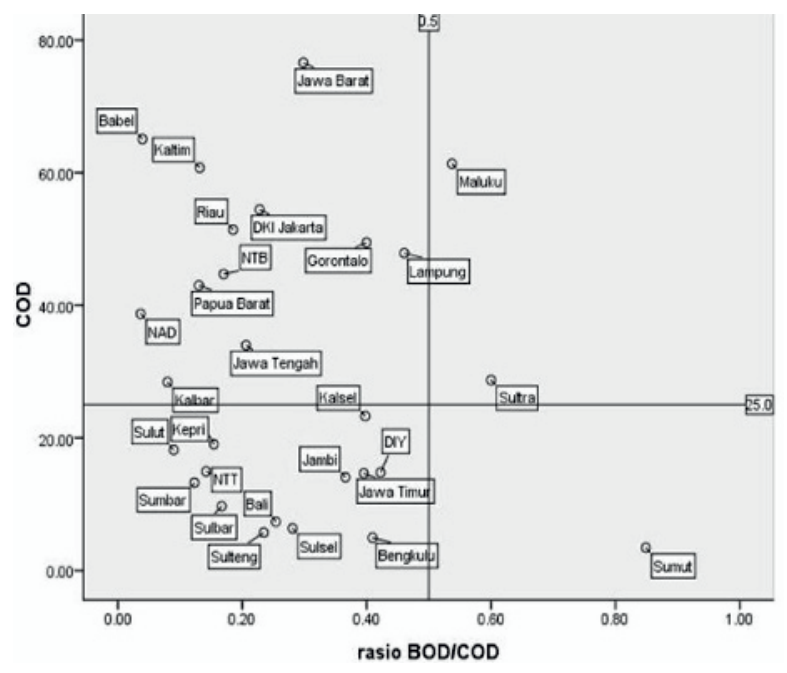

Figure 9. Indonesia River Condition in 2012

\section{Conclusions and Recommendation}

Successfully applying technology in the purified water system of the pharmaceutical industry will be comply the CPOB Indonesia stated by the NADFC/BPOM's regulation No. HK. 03.1.33.12.12 year 2012 was regarding how to process, produce, maintain and sanitation of the purified water system (generation and looping) for pharmaceutical industry in Indonesia.

Base on the datas what we have shown, the chemical process of water treatment compare to the membrane technology with the cost of membrance more economical. And the chemical water treatment process still have an issues in the hazard of waste. Relating to the operational cost of treated in every litre of waste water influent, the operational cost average IDR.129/1tr.[2].

And the chemical treated water system have an potential issues in bacteria and viruses contamination, due the capability of this type of treatment only remove between 27 and 84 percent of viruses and between 32 and 87 percent of bacteria. $^{3}$

The membrane technology of water treatment is the best option to reduce or eliminate the cost and hazard of regenerating of chemical consumption (acid and caustic) and the cost of regeneration water disposal, treatment plants can be incorporated with pre-treatment technology and Reverse Osmosis (RO), Electrodeionization (EDI) technology [8], and Ultra Violet (UV) to bacteria control, that can cost-effectively replace the chemical water treatment system, and reducing the environmental pollution, also have a better and sustainable quality of the water treatment process.

Implementation of free chemical purification water treatment with series of system has explained in above, will reduce a huge operational cost, and save the Indonesia river from pollution.

This brief comparative overview of research of this paper has identified some potential areas of purified water system of pharmaceutical industry in CPOB Indonesia to help others pharmaceutical companies to survive under BPOM's regulation. Although there are lots of questions, discussions and debates regarding the constraints of BPOM's regulation and cost of investment of this purified water system, we strongly believe there is a huge potential and opportunities in pharmaceutical industry of Indonesian market. Of course, further research regarding the cost of purified water system and the constraints of BPOM's regulation need to be further elaborate.

Another important topic in the business practices is to reducing the capital cost of installation of this series water treatment system in the small pharmaceutical company.

\section{Appendix A. Type and specification of membrane technology}

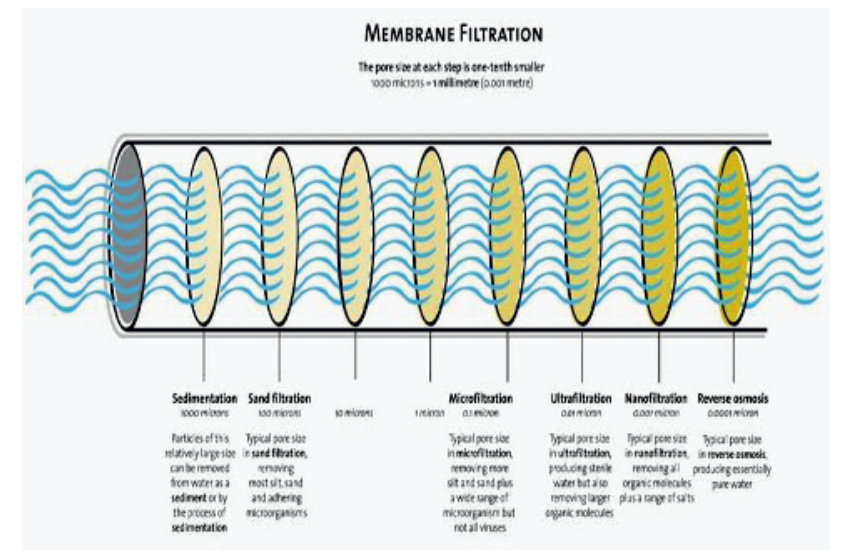


Appendix B. Reverse Osmosis membrane technology

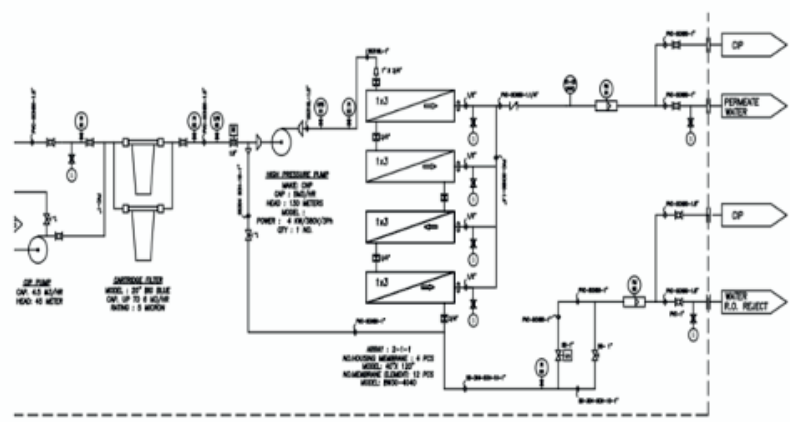

\section{Appendix C. Trend of pollution in Indonesia river water by parameter}

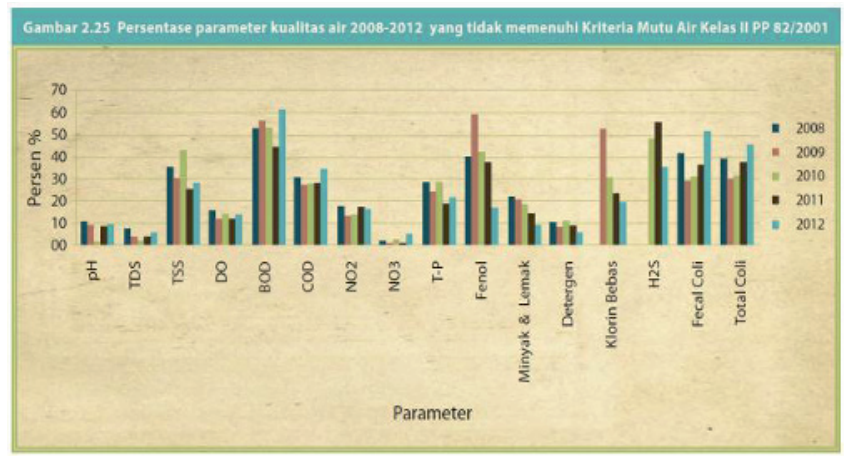

organizational fields", American Sociological Review, 48 (1983), 147-60.

[11] Rivero, A. T., et. Al. (2007) Improving a pharmaceutical water system based on a Risk Analysis Approach. Pharmaceutical Technology; Nov 2007; 31, 11; ProQuest Research Library pg. 60.

[12] Status Lingkungan Hidup Indonesia, 2012, Kementerian Lingkungan Hidup Republik Indonesia,2012,pp. 43-45.

[13] Thomas, T. (1998) Technology in the Pharmaceutical Industry: The Patient is Waiting Vital Speeches of the Day; Nov 1, 1998; 65, 2; ProQuest Research.

\section{References}

[1] Business Monitor International (2010) Indonesia Pharmaceuticals \& Healthcare Report Q3 2010, Business Monitor International Ltd. ISSN 1748-1945

[2] Dian Risdianto, "Optimisasi Proses Koagulasi Floculasi Untuk Pengolahan Air Limbah Industri Jamu", Disertation for Master of Chemical Engineering, Diponegoro University, Semarang, 2007.

[3] International Trade Center (2005), Supply and demand survey on pharmaceuticals and natural products-Indonesia, International Trade Center, July 2005.

[4] Joshi, H. N. (2003), Analysis of the Indian Pharmaceutical Industry with Emphasis on opportunities in 2005. Pharmaceutical Technology North America; Jan 2003; 27,1; ProQuest Research Library pg. 74.

[5] June, E. (2004), Information retrieval in the pharmaceutical industry. Pharmaceutical Technology; 2004; ProQuest Research Library pg. $S 8$.

[6] Lin, B., \& Dwyer, D.S. (1995) New product development in the information age: pharmaceutical industry. The Journal of Business \& Industrial Marketing; 1995; 10, 3; ProQuest Research Library pg. 6 .

[7] Mazzola, et, al (2006) Chemical resistance of the gram-negative bacteria to different sanitizers in a water purifications system. BMC Infectious Disease.

[8] Paul, D. H. (2002) Electrodeionization in pharmaceutical water treatment, Pharmaceutical Technology North America; Jul; 26, 7; ProQuest Research Library pg. 36.

[9] Pfeffer, J., \& Salancik, G. R. 2003. The external control of organizations: A resource dependence perspective: Stanford, CA: Stanford University Press.

[10] P. J. DiMaggio \& W. Powell, "The iron cage revisited" institutional isomorphism and collective rationality in 